\title{
Simulation of medicanes over the Mediterranean Sea in a regional climate model ensemble: impact of ocean-atmosphere coupling and increased resolution
}

\author{
Miguel Ángel Gaertner ${ }^{1} \cdot$ Juan Jesús González-Alemán ${ }^{1} \cdot$ Raquel Romera $^{1} \cdot$ Marta Domínguez $^{1} \cdot$ Victoria Gil $^{1}$ \\ Enrique Sánchez $^{1}$ - Clemente Gallardo ${ }^{1}$. Mario Marcello Miglietta ${ }^{2} \cdot$ Kevin J. E. Walsh ${ }^{3} \cdot$ Dmitry V. Sein $^{4}$. \\ Samuel Somot ${ }^{5}$ - Alessandro Dell'Aquila ${ }^{6}$. Claas Teichmann ${ }^{7} \cdot$ Bodo Ahrens $^{8} \cdot$ Erasmo Buonomo $^{9}$. \\ Augustin Colette $^{10} \cdot$ Sophie Bastin $^{11} \cdot$ Erik van Meijgaard $^{12} \cdot$ Grigory Nikulin $^{13}$
}

Received: 1 May 2016 / Accepted: 13 November 2016

(C) Springer-Verlag Berlin Heidelberg 2016

\begin{abstract}
Medicanes are cyclones over the Mediterranean Sea having a tropical-like structure but a rather small size, that can produce significant damage due to the combination of intense winds and heavy precipitation. Future climate projections, performed generally with individual atmospheric climate models, indicate that the intensity of the medicanes could increase under climate change conditions. The availability of large ensembles of high resolution and oceanatmosphere coupled regional climate model (RCM) simulations, performed in MedCORDEX and EURO-CORDEX projects, represents an opportunity to improve the assessment of the impact of climate change on medicanes. As a first step towards such an improved assessment, we analyze the ability of the RCMs used in these projects to reproduce the observed characteristics of medicanes, and the impact of
\end{abstract}

This paper is a contribution to the special issue on MedCORDEX, an international coordinated initiative dedicated to the multi-component regional climate modelling (atmosphere, ocean, land surface, river) of the Mediterranean under the umbrella of HyMeX, CORDEX, and Med-CLIVAR and coordinated by Samuel Somot, Paolo Ruti, Erika Coppola, Gianmaria Sannino, Bodo Ahrens, and Gabriel Jordà.

Miguel Ángel Gaertner

Miguel.Gaertner@uclm.es

1 Universidad de Castilla-La Mancha, Toledo, Spain

2 Institute of Atmospheric Sciences and Climate - National Research Council (ISAC-CNR), Lecce, Italy

3 University of Melbourne, Parkville, Australia

4 Alfred Wegener Institute, Bremerhaven, Germany

5 CNRM UMR 3589, Météo-France/CNRS, Toulouse, France

6 ENEA, SSPT-MET-CLIM, Rome, Italy

7 Climate Service Center Germany (GERICS), Hamburg, Germany increased resolution and air-sea coupling on their simulation. In these storms, air-sea interaction plays a fundamental role in their formation and intensification, a different mechanism from that of extra-tropical cyclones, where the baroclinic instability mechanism prevails. An observational database, based on satellite images combined with high resolution simulations (Miglietta et al. in Geophys Res Lett 40:24002405,2013 ), is used as a reference for evaluating the simulations. In general, the simulated medicanes do not coincide on a case-by-case basis with the observed medicanes. However, observed medicanes with a high intensity and relatively long duration of tropical characteristics are better replicated in simulations. The observed spatial distribution of medicanes is generally well simulated, while the monthly distribution reveals the difficulty of simulating the medicanes that first appear in September after the summer minimum in occurrence. Increasing the horizontal resolution has a systematic and generally positive impact on the frequency of simulated medicanes, while the general underestimation of their intensity is not corrected in most cases. The capacity of a few models to better simulate the medicane intensity suggests

8 Institute for Atmospheric and Environmental Sciences, Goethe-University Frankfurt, Frankfurt am Main, Germany

9 Met Office-Hadley Centre, Exeter, United Kingdom

10 Institut National de l'Environnement Industriel et des Risques (INERIS), Verneuil-en-Halatte, France

11 LATMOS/IPSL, CNRS/INSU, UVSQ Université Paris-Saclay, UPMC Univ. Paris 06, Guyancourt, France

12 Royal Netherlands Meteorological Institute (KNMI), De Bilt, The Netherlands

13 Rossby Centre, Swedish Meteorological and Hydrological Institute, Norrköping, Sweden 
that the model formulation is more important than reducing the grid spacing alone. A negative intensity feedback is frequently the result of air-sea interaction for tropical cyclones in other basins. The introduction of air-sea coupling in the present simulations has an overall limited impact on medicane frequency and intensity, but it produces an interesting seasonal shift of the simulated medicanes from autumn to winter. This fact, together with the analysis of two contrasting particular cases, indicates that the negative feedback could be limited or even absent in certain situations. We suggest that the effects of air-sea interaction on medicanes may depend on the oceanic mixed layer depth, thus increasing the applicability of ocean-atmosphere coupled RCMs for climate change analysis of this kind of cyclones.

Keywords Mediterranean cyclones $\cdot$ Medicanes $\cdot$ Regional climate models · High resolution · Ocean-atmosphere coupling

\section{Introduction}

Medicanes (Mediterranean tropical-like cyclones) are a particular kind of cyclones that are observed sporadically over the Mediterranean Sea. Their diameter is rather small, typically less than $300 \mathrm{~km}$ and they generally present a symmetrical cloud structure around a cloudless eye (Fita et al. 2007), which indicates tropical characteristics like a warm core and a predominant role of air-sea fluxes and convection in their development and maintenance. They form from baroclinic cut-off lows, evolving into a warm core cyclone through tropical transition (Emanuel 2005; Chaboureau et al. 2012). Medicanes can produce considerable damage due to the combination of intense winds and heavy precipitation. Observed cases of tropical-like cyclones in the Mediterranean region have been analyzed in detail (Pytharoulis et al. 2000; Reale and Atlas 2001; Homar et al. 2003; Moscatello et al. 2008).

Cyclones with partial tropical characteristics occur in other basins of the world as well. For example, subtropical cyclones have been observed in the Atlantic Ocean (Guishard et al. 2009; Evans and Braun 2012; GonzálezAlemán et al. 2015) and in the Pacific Ocean (Garde et al. 2010). There is no clear-cut separation between tropical and extratropical cyclones. Hart (2003) developed a classification method, the cyclone phase space analysis, in which the different cyclone types form a continuum, and transitions between extra-tropical and tropical cyclones are smoothly integrated. Medicanes can attain fully tropical characteristics during their lifetime, but this tropical phase is generally rather short (Miglietta et al. 2013).

The small size of medicanes and the sparse data available over the sea, where they develop, complicate the analysis of their climatological characteristics. Reanalysis data are too coarse for detecting and characterizing medicanes adequately. This has led to the use of satellite data as the main way for obtaining databases of medicanes (Tous and Romero 2013). Miglietta et al. (2013) combined satellite data and high resolution limited area meteorological model simulations to identify additional aspects of medicanes such as their warm core structure and high low-level wind speed. A long-term climatology has been derived by Cavicchia et al. (2013) through dynamical downscaling of six decades of reanalysis, applying a regional climate model (RCM) with spectral nudging. The spatial distribution of medicanes is very similar in these climatologies, with two maxima over the Western Mediterranean and the Ionian Sea, respectively. This distribution differs clearly from that of the most frequent extratropical Mediterranean cyclones. The seasonal distribution shows the highest activity in autumn and winter, while very few medicanes are seen during summer, despite the high sea surface temperature (SST) in this season. The frequency of medicanes depends on the selection criteria, ranging from 0.5 to about 1.5 medicanes per year in the three databases mentioned above.

In the frame of the impacts of climate change on tropical cyclones, an important issue is whether areas that support now only marginally the development of tropical cyclones, like the Mediterranean Sea, will experience an increase of tropical cyclone activity in the future. A potential result of anthropogenic climate change is the poleward extension of the effects of tropical cyclones (Walsh et al. 2016). The latitude at which tropical cyclones reach their maximum intensity has already shifted poleward during the last decades (Kossin et al. 2014). In this context, the future variations of medicane characteristics due to climate change are a matter of concern. RCMs have been used to downscale global climate model (GCM) scenarios (Gaertner et al. 2007; Cavicchia et al. 2014; Walsh et al. 2014). Romero and Emanuel (2013) applied a statistical-deterministic method for increasing the medicane sample size. Tous et al. (2016) used a high resolution global climate simulation to analyze future medicane changes. A consistent result is a reduction in the frequency of medicanes under future climate conditions, together with an intensity increase for the most intense medicanes.

For the climatological analysis of medicanes, dynamical downscaling with RCMs has some advantages. This technique can produce high resolution results, which are fundamental for representing medicanes, and can include feedbacks that can affect their development, like the impact of oceanatmosphere coupling. Considering that air-sea coupling generates typically a negative feedback on the intensity of tropical cyclones, through vertical mixing of the oceanic column (Emanuel 1999), we could expect a similar intensity reduction on medicanes, at least for the most intense cyclones. The coupling takes into account that deeper cold water can be brought to the surface, reducing the sea surface temperature 
and, as a consequence, the latent and sensible heat fluxes to the atmosphere, which play a key role in the intensification of medicanes. The analysis of the effect of air-sea coupling on medicane simulation is one aim of the present study. This kind of analysis has been performed previously by Akhtar et al. (2014), which used only one atmospheric model coupled to a simplified 1-D ocean model, while here we use a multi-model ensemble of simulations with 3-D ocean models.

Here we analyze the ability of RCMs to simulate medicanes, using a large multi-model ensemble of RCM simulations from EURO-CORDEX (Jacob et al. 2014) and Med-CORDEX (Ruti et al. 2015) projects. Though GCM simulations, with a similar resolution as the RCM simulations used here, are also available, these GCM simulations are not adequate for the present study due to several reasons. There are only few such high-resolution GCM runs. These GCM simulations have been performed without coupling to the ocean and typically cover only short time periods, which is not appropriate here due to the large interannual variability of the medicane frequency. Finally, such GCM runs are not part of coordinated multi-model experiments, in contrast to the RCM simulations used here. The use of many different models represents an advance with respect to previous medicane simulation studies, and allows us to consider the uncertainty linked to differences in model formulation. EUROCORDEX and Med-CORDEX ensembles are particularly valuable for the analysis of medicanes, as they include high resolution (up to $10 \mathrm{~km}$ ) and atmosphere-ocean coupled runs. This will allow us to assess the impact of increased resolution and air-sea coupling on the simulation of medicanes in RCMs. The present analysis is part of a broader effort to obtain an improved assessment of the effects of anthropogenic climate change on medicanes. In this respect, the use of EURO-CORDEX and Med-CORDEX simulations is also advantageous, as they include a very large number of future climate projections using the same RCMs analyzed here.

\section{Method and data}

We have used a total of 29 simulations from the Med-CORDEX and EURO-CORDEX projects, all nested in ERAInterim reanalysis, with the exception of AWI simulations which have been nested in ERA-40 reanalysis and cover a much bigger domain, including the Atlantic tropical region. The following list indicates the institution acronym, followed by the RCMs used. The most relevant information for the purposes of the paper is included in brackets (coupled or uncoupled RCM; horizontal resolution in $\mathrm{km}$ ), and the simulation periods are also shown:

- AWI/GERICS: REMO (uncoupled; 50, 25 and $18 \mathrm{~km}$ ) and ROM [coupled; 50, 25 and $18 \mathrm{~km}$ (Sein et al.
2015)]. Simulation periods: 1982-2001 (50 km runs), 1978-2001 (25 km runs), 1975-2001 (18 km runs)

- CNRM: ALADIN5.2 [uncoupled; 50 and $12.5 \mathrm{~km}$ (Colin et al. 2010; Herrmann et al. 2011)] and RCSM4 [coupled; $50 \mathrm{~km}$ (Sevault et al. 2014)]. Simulation periods: 1979-2011 (ALADIN5.2 runs), 1980-2011 (RCSM4 run)

- ENEA: REGCM [uncoupled; $25 \mathrm{~km}$ (Artale et al. 2010)] and PROTHEUS [coupled; $25 \mathrm{~km}$ (Artale et al. 2010)]. Simulation period: 1982-2010

- GERICS: REMO [uncoupled; 50 and $12.5 \mathrm{~km}$ (Jacob et al. 2012)] Simulation period: 1989-2008

- GUF: CCLM 4-8-18 [uncoupled; 50 and $10 \mathrm{~km}$ (Rockel et al. 2008; Kothe et al. 2014)]. Simulation period: 1989-2008

- IPSL-INERIS: WRF [uncoupled; 50 and $12.5 \mathrm{~km}$ (Vautard et al. 2013)]. Simulation period: 1989-2008

- IPSL: WRF3.1.1 (uncoupled; $50 \mathrm{~km}$ [Skamarock et al. 2008; Flaounas et al. 2013; Stéfanon et al. 2014)] and WRF3.1.1-NEMO [coupled; $50 \mathrm{~km}$ (Brossier et al. 2015)]. Simulation period: $1989-2008$

- KNMI: RACMO22E [uncoupled; 50 and $12.5 \mathrm{~km}$ (van Meijgaard et al. 2012)]. Simulation period: 1989-2008

- MET(Office): HadGEM3 [uncoupled; 50, 25 and $12.5 \mathrm{~km}$ (Moufouma-Okia and Jones 2014)]. Simulation period: 1990-2010

- SMHI: RCA4 [uncoupled; 50 and $12.5 \mathrm{~km}$ (Kupiainen et al. 2011; Samuelsson et al. 2011)]. Simulation period: 1980-2010

- UCLM: PROMES [uncoupled; 50, 25 and $12.5 \mathrm{~km}$ (Domínguez et al. 2010, 2013)]. Simulation period: 1989-2008

As the aim of this study is to analyze the impact of high resolution and air-sea coupling on the simulation of medicanes, we have grouped the simulations into pairs of low/ high resolution simulations and pairs of uncoupled/coupled simulations with the same atmospheric RCM. Multi-model ensembles of such simulation pairs are then used for the evaluation of the RCM ability to simulate medicanes. The different simulations are identified by combining the acronyms of the institution and the model plus the horizontal resolution in $\mathrm{km}$ (e.g., AWI-REMO-50).

The cyclone detection and tracking method of Picornell et al. (2001) is applied for detecting cyclones. This method is designed particularly for mesoscale cyclones, and is therefore especially suited to the detection of medicanes. The detection of lows is based on sea level pressure (SLP), and wind at $700 \mathrm{hPa}$ is used as an auxiliary variable for the tracking. The cyclone intensity is represented by the daily maximum surface wind, calculated within a radius of $400 \mathrm{~km}$ from the cyclone center. Only cyclones exceeding tropical storm intensity $(17.5 \mathrm{~m} / \mathrm{s}$ surface wind speed) are considered. 
As medicanes have tropical characteristics, we can identify them by using the cyclone phase space (CPS) method of Hart (2003), by which a cyclone is classified as tropical if it is thermally symmetric (it has no frontal structure) and has a full-tropospheric warm core. These features are measured by three parameters: $\mathrm{B},-\mathrm{V}_{\mathrm{T}}^{\mathrm{L}}$ and $-\mathrm{V}_{\mathrm{T}}^{\mathrm{U}}$, derived from the geopotential values between 900 and $300 \mathrm{hPa}$. B represents the horizontal thermal symmetry of the cyclone, with positive values above $10 \mathrm{~m}$ indicating an asymmetric (frontal) cyclone, and values below that threshold indicating a symmetric (non-frontal) cyclone. The thermal wind parameters for the lower troposphere $\left(-\mathrm{V}_{\mathrm{T}}^{\mathrm{L}}\right)$ and the upper troposphere $\left(-\mathrm{V}_{\mathrm{T}}^{\mathrm{U}}\right)$ describe the warm or cold core structure of the cyclone. Positive values indicate a warm core and negative values a cold core. Due to the small diameters of medicanes, we have applied the CPS criteria around a radius of only $150 \mathrm{~km}$ from the low pressure center. The CPS method is a compact and objective way to represent the 3D structure of a cyclone and detect if it has tropical characteristics.

Taking into account the huge amount of data to analyze and the highly time-consuming methods applied, we have limited our analysis to the months with higher medicane frequency. Medicanes appear more frequently in autumn and winter, so we have focused our analysis on the months from August to January. For the same reason, and also because some fields necessary for our analysis were not available at 6-hourly time resolution, we use daily average values of the different variables, instead of 6-hourly values. This has the side effect of not allowing the calculation of the B parameter for cyclones lasting only 1 day. A sequence of at least two low centers is needed to identify the displacement direction necessary for calculating B. Due to this limitation, we have not considered the B parameter for selecting tropical cyclones.

The medicane database developed by Miglietta et al. (2013), covering the 1999-2012 period, has been used as reference for evaluating the simulation results. In this database, observed medicane cases selected through satellite images are simulated with a high resolution model, and only those cyclones showing a fully tropical structure for at least $6 \mathrm{~h}$ are considered as medicanes. This criterion has been adapted for comparison with the daily data used here. For daily average data, a cyclone is considered to be a medicane if $-\mathrm{V}_{\mathrm{T}}^{\mathrm{L}}>0$ (lower warm core) and $-\mathrm{V}_{\mathrm{T}}^{\mathrm{U}}>-10$ (upper warm core or nearly warm core). The latter value is a threshold selected in order to classify as medicanes also those cyclones that have an upper warm core lasting for less than 1 day. In the following, the location of the medicanes corresponds to the points where the cyclones reach their maximum intensity in the phase with tropical-like characteristics.
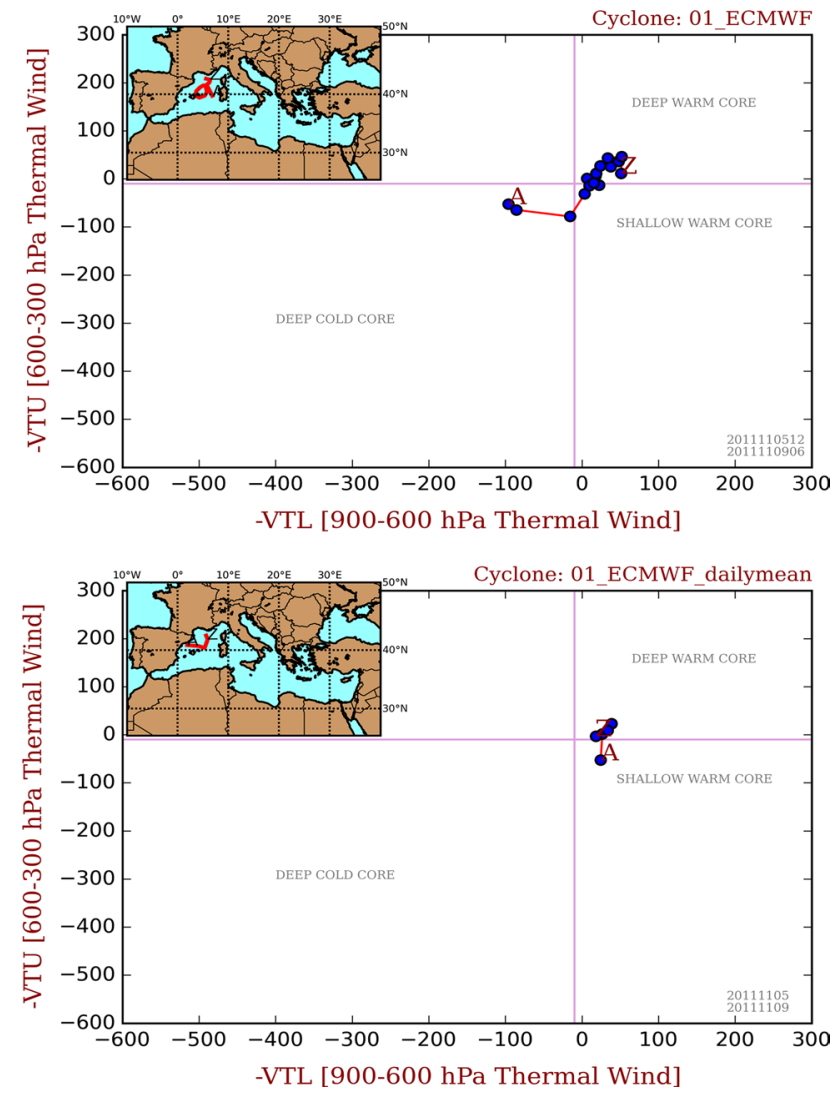

Fig. 1 Cyclone phase space (CPS) analysis for the observed medicane of November 2011, calculated for 6-hourly (upper panel) and daily mean (lower panel) geopotential values of the ECMWF operational analysis. The two parameters represented in the diagram are $-\mathrm{V}_{\mathrm{T}}^{\mathrm{L}}$ (lower-tropospheric thermal wind parameter, indicating a lowertropospheric cold core if it has negative values and a lower-tropospheric warm core if it has positive values) and $-\mathrm{V}_{\mathrm{T}}^{\mathrm{U}}$ (upper-tropospheric thermal wind parameter, indicating an upper-tropospheric cold core if it has negative values and an upper-tropospheric warm core if it has positive values). Extratropical cyclones are represented in the lower left quadrant, while tropical cyclones are represented in the upper right quadrant. The cyclone track is indicated in red in the upper left inset of the panels. The beginning of the cyclone evolution in the CPS is indicated trough an "A", while the end is indicated through a " $Z$ "

In order to illustrate how the CPS method represents the tropical characteristics of medicanes and their formation mechanism, we show in Fig. 1 the specific case of the medicane observed in November 2011. Using 6-hourly data from the operational ECMWF analysis, the evolution of the cyclone in the cyclone phase space is shown in the upper panel of Fig. 1. The cyclone begins as a cold-core extratropical low and experiences a tropical transition, acquiring a full-tropospheric warm core. In this case, the medicane maintained a tropical structure during more than two days. The effect of using daily average data is shown in the lower panel of Fig. 1. The evolution of the cyclone is clearly more 
limited than for 6-hourly data, as the daily average values indicate a hybrid structure in the first day (with a lowertropospheric warm core and upper-tropospheric cold core), and the maximum values of the thermal wind parameters are smaller (indicating a less intense warm core during the fully tropical phase). However, the daily values are sufficient to detect the tropical structure of the medicane, supporting their use in the present study.

\section{Results and discussion}

\subsection{Simulation of observed medicanes}

The tropical transition, responsible for the generation of medicanes, is a very complex mechanism, as shown for example by Davis and Bosart (2004) or Moscatello et al. (2008). It depends on synoptic features (an upper level cut-off low, vertical wind shear), on local air-sea interactions and on small-scale processes (convection developing around the location of the low and liberating latent heat) that are parameterized in climate models. This combination of factors makes the simulation of tropical transitions a challenging issue. It is not clear whether climatemode simulations can reproduce in a deterministic way the observed medicanes, as no reinitialization of atmospheric fields is done in the domain interior after the beginning of the simulation. Medicanes form well within the model domains, which means that their tropical characteristics are not directly transmitted through the lateral boundary conditions.

In order to analyze the correspondence between simulated and observed medicanes, we have compared their dates and locations. Some margin has been allowed in this comparison, so that simulated medicanes found within $10^{\circ}$ of the observed location, or up to two days before or after the observed medicanes (if they form under the same cutoff low) have been considered as corresponding to the same case.

Table 1 shows the set of high-intensity medicanes (maximum surface winds above $25.5 \mathrm{~m} / \mathrm{s}$ ) and Table 2 the set of moderate-intensity medicanes (maximum surface winds between 17.5 and $25.5 \mathrm{~m} / \mathrm{s}$ ) registered in the reference database from Miglietta et al. (2013). The cases in which the RCMs indeed simulate a medicane are indicated in red. There are rather few full matches between the two sets, as can be seen in Tables 1 and 2. This confirms a previous result obtained by Walsh et al. (2014) using one RCM, in which most of the simulated medicanes did not correspond to observed cases. They pointed to the stochastic processes dominating the formation of such small-size cyclones as a reason for this result.
In our study, there are additional possible reasons for the absence of correspondence between simulations and observations. The duration of the phase with tropical characteristics in the observed cases is generally limited to a few hours, which is below the time resolution available in the simulation outputs considered here. In this respect, it is noteworthy that medicanes with a longer persistence of tropical features are more frequently reproduced in the simulations. The medicane in December 2005 (reproduced as a warm-core cyclone by five simulations) had a tropical structure during $33 \mathrm{~h}$, and reached maximum $10 \mathrm{~m}$ winds of $33 \mathrm{~m} / \mathrm{s}$, while the medicane in November 2011 had a tropical phase of $63 \mathrm{~h}$, and maximum $10 \mathrm{~m}$ winds of $32 \mathrm{~m} / \mathrm{s}$. The latter case is reproduced by all three available simulations (CNRM) as a medicane, as shown by the CPS analysis in Fig. 2. The evolution in the cyclone phase space compares really well with the results from the ECMWF reanalysis shown in Fig. 1. Even the two lower resolution simulations with CNRM models are able to detect a fully tropical structure for 2 days. The November 2011 medicane shows a remarkable reproducibility, compared to the other storms. No other simulation reached the year 2011, so this case cannot be analyzed using other models.

A clear factor affecting the simulation of medicanes is their intensity. Lower-intensity medicanes (Table 2) are not replicated by most models. More coincidences between simulated and observed medicanes are found for higherintensity medicanes (Table 1). Davis and Bosart (2004) distinguish two types of tropical transition, depending on the amplitude of the precursor disturbance: in transitions originated by strong extratropical cyclones, wind-induced surface heat exchange (WISHE; Emanuel (1987)) is the key process, while in cases where the precursor is a weak extratropical cyclone, this extra-tropical disturbance is an organizing factor for the convection, which must then experience self-organization to generate a self-amplifying cyclone. This could explain in part the different degree of reproducibility of some medicanes: the two cases cited above, which are better reproduced by the models, correspond to strong and large upper-level cut-off lows. In contrast, the medicane in September 2006 formed under a comparatively weak disturbance, and is not reproduced in most simulations. The cases coincident in simulations and observations show no preference for a particular model configuration or resolution.

There are several possibilities for the missed simulation of an observed medicane. The tropical transition could be only partially simulated, resulting in a hybrid cyclone with a lower-tropospheric warm core and upper-tropospheric cold core. Also, the simulated cyclone could maintain its original cold-core structure, or might not reach the threshold of $17.5 \mathrm{~m} / \mathrm{s}$ (maximum surface wind) used in our 
Table 1 Coincidences between simulated cyclones and observed high-intensity medicanes (maximum winds $>25.5 \mathrm{~m} / \mathrm{s}$ )

\begin{tabular}{|c|c|c|c|c|c|c|c|}
\hline & $\begin{array}{c}17-18 / 10 \\
2003\end{array}$ & $\begin{array}{c}3-6 / 11 \\
2004\end{array}$ & $\begin{array}{c}13-15 / 12 \\
2005\end{array}$ & $\begin{array}{l}26 / 9 \\
2006\end{array}$ & $\begin{array}{c}26 / 10 \\
2007\end{array}$ & $\begin{array}{l}4 / 12 \\
2008\end{array}$ & $\begin{array}{c}6-8 / 11 \\
2011\end{array}$ \\
\hline AWI/GERICS-REMO-18 & & & & & & & $\mathbf{X}$ \\
\hline AWI/GERICS-ROM-18 & & & & & & & $\mathbf{X}$ \\
\hline AWI/GERICS-REMO-25 & & & & & & & $\mathbf{X}$ \\
\hline AWI/GERICS-ROM-25 & & & & & & & $\mathbf{X}$ \\
\hline AWI/GERICS-REMO-50 & & & & & & & $\mathbf{X}$ \\
\hline AWI/GERICS-ROM-50 & & & & & & & $\mathbf{X}$ \\
\hline \multicolumn{8}{|l|}{ CNRM-ALADIN52-12 } \\
\hline \multicolumn{8}{|l|}{ CNRM-ALADIN52-50 } \\
\hline \multicolumn{8}{|l|}{ CNRM-RCSM4-50 } \\
\hline ENEA-REGCM & & & & & & & $\mathbf{X}$ \\
\hline ENEA-PROTHEUS & & & & & & & $\mathbf{X}$ \\
\hline GERICS-REMO-12 & & & & & & & $\mathbf{X}$ \\
\hline GERICS-REMO-50 & & & & & & & $\mathbf{X}$ \\
\hline GUF-CCLM4-10 & & & & & & & $\mathbf{X}$ \\
\hline GUF-CCLM4-50 & & & & & & & $\mathbf{X}$ \\
\hline INERIS-WRF-12 & & & & & & & $\mathbf{X}$ \\
\hline INERIS-WRF-50 & & & & & & & $\mathbf{X}$ \\
\hline IPSL-WRF311 & & & & & & & $\mathbf{X}$ \\
\hline IPSL-WRF311-NEMO & & & & & & & $\mathbf{X}$ \\
\hline KNMI-RACMO22E-12 & & & & & & & $\mathbf{X}$ \\
\hline KNMI-RACMO22E-50 & & & & & & & $\mathbf{X}$ \\
\hline MET-HadGEM3-12 & & & & & & & $\mathbf{X}$ \\
\hline MET-HadGEM3-25 & & & & & & & $\mathbf{X}$ \\
\hline MET-HadGEM3-50 & & & & & & & $\mathbf{X}$ \\
\hline SMHI-RCA4-12 & & & & & & & $\mathbf{X}$ \\
\hline SMHI-RCA4-50 & & & & & & & $\mathbf{X}$ \\
\hline UCLM-PROMES-12 & & & & & & & $\mathbf{X}$ \\
\hline UCLM-PROMES-25 & & & & & & & $\mathbf{X}$ \\
\hline UCLM-PROMES-50 & & & & & & & $\mathbf{X}$ \\
\hline
\end{tabular}

Colors indicate the type of simulated cyclone: red indicates a warm-core, grey a hybrid and blue a cold-core cyclone. The dates are taken from Miglietta et al. (2013). The "X" indicates that year 2011 was not included in the simulation period of the corresponding models

detection method. We have examined these possibilities. Simulated cyclones with a hybrid structure are shown in grey, and simulated cyclones with a cold-core are marked in blue in Tables 1 and 2. An empty cell indicates that no cyclone with intensity above $17.5 \mathrm{~m} / \mathrm{s}$ has been simulated.
Hybrid and cold-core cyclones are simulated much more frequently in cases of high-intensity observed medicanes than of moderate-intensity observed medicanes. It is clearly more likely that models simulate a cyclone corresponding to an actually observed medicane if the latter is 
Table 2 As in Table 1, but for moderate-intensity observed medicanes (maximum winds between 17.5 and $25.5 \mathrm{~m} / \mathrm{s}$ )

\begin{tabular}{|l|l|l|l|l|l|}
\hline & $\begin{array}{c}\mathbf{1 3 / 0 9} \\
\mathbf{1 9 9 9}\end{array}$ & $\begin{array}{c}\mathbf{1 0 - 1 1 / 0 9} \\
\mathbf{2 0 0 0}\end{array}$ & $\begin{array}{c}\mathbf{9} / \mathbf{1 0} \\
\mathbf{2 0 0 0}\end{array}$ & $\begin{array}{c}\mathbf{2 1 / 0 9} \\
\mathbf{2 0 0 4}\end{array}$ & $\begin{array}{c}\mathbf{1 7 / 1 0} \\
\mathbf{2 0 0 7}\end{array}$ \\
\hline AWI/GERICS-REMO-18 & & & & & \\
\hline AWI/GERICS-ROM-18 & & & & & \\
\hline AWI/GERICS-REMO-25 & & & & & \\
\hline AWI/GERICS-ROM-25 & & & & & \\
\hline AWI/GERICS-REMO-50 & & & & & \\
\hline AWI/GERICS-ROM-50 & & & & & \\
\hline CNRM-ALADIN52-12 & & & & & \\
\hline CNRM-ALADIN52-50 & & & & & \\
\hline CNRM-RCSM4-50 & & & & & \\
\hline ENEA-REGCM & & & & & \\
\hline ENEA-PROTHEUS & & & & & \\
\hline GERICS-REMO-12 & & & & & \\
\hline GERICS-REMO-50 & & & & & \\
\hline GUF-CCLM4-10 & & & & & \\
\hline GUF-CCLM4-50 & & & & & \\
\hline INERIS-WRF-12 & & & & & \\
\hline INERIS-WRF-50 & & & & & \\
\hline IPSL-WRF311 & & & & & \\
\hline IPSL-WRF311-NEMO & & & & & \\
\hline KNMI-RACMO22E-12 & & & & & \\
\hline KNMI-RACMO22E-50 & & & & & \\
\hline MET-HadGEM3-12 & & & & & \\
\hline MET-HadGEM3-25 & & & & \\
\hline MET-HadGEM3-50 & & & & \\
\hline SMHI-RCA4-12 & & & & \\
\hline SMHI-RCA4-50 & & & & \\
\hline UCLM-PROMES-12 & & & & \\
\hline UCLM-PROMES-50 & & & & \\
\hline
\end{tabular}

intense. The case of IPSL-WRF311, which employs spectral nudging, is revealing in this aspect. All high-intensity medicanes are replicated by this model as cold-core, hybrid or warm-core cyclones; but only one out of five less intense medicanes is captured by it. The same happens with MET-HadGEM3-12 simulation. This behaviour is likely associated to the general underestimation of intensity in the simulations. Observed medicanes with intensity above $25.5 \mathrm{~m} / \mathrm{s}$ are generally simulated as cyclones with intensities below this threshold, and observed medicanes with intensity between 17.5 and $25.5 \mathrm{~m} / \mathrm{s}$ do not reach the $17.5 \mathrm{~m} / \mathrm{s}$ threshold in many simulations. Another factor contributing to this model deficiency could be the smaller size of the less intense observed medicanes, which limits the ability of the models to capture them. But the lack of clear differences between low and high resolution simulations in Tables 1 and 2 suggests that this is not a major factor.

The ability of models to simulate at least partially tropical characteristics also seems to depend on the intensity 

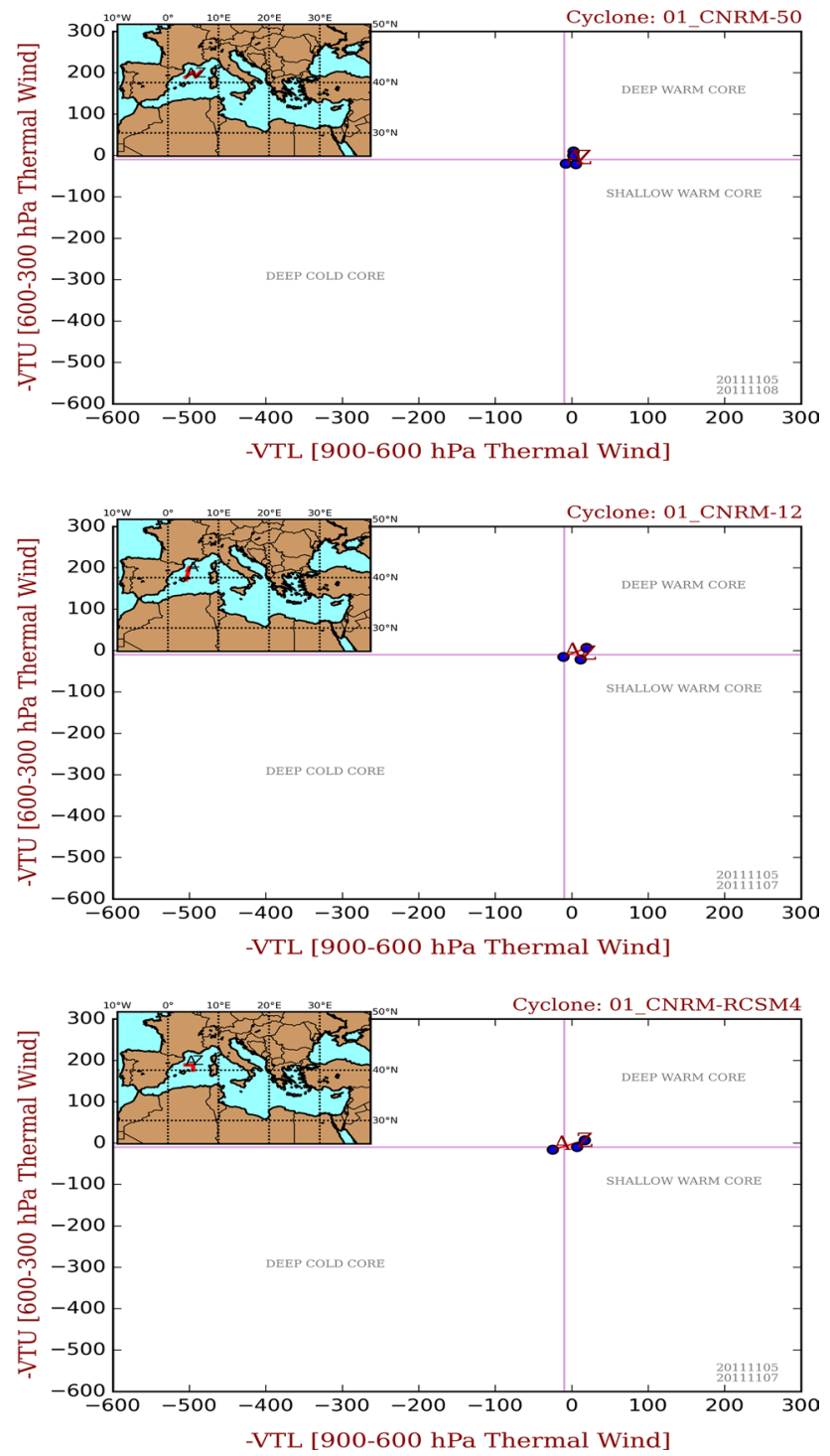

Fig. 2 CPS diagrams as in Fig. 1, for the same medicane case of November 2011, but for daily mean values of the uncoupled CNRMALADIN52 simulation at $50 \mathrm{~km}$ resolution (upper panel), uncoupled CNRM-ALADIN52 simulation at $12 \mathrm{~km}$ resolution (middle panel) and coupled CNRM-RCSM4 simulation at $50 \mathrm{~km}$ resolution (lower panel)

of observed medicanes. Table 1 includes more hybrid and warm-core cyclones than cold-core cyclones in the simulations. The opposite comes out for the less intense medicanes, as a large majority of the simulated cyclones in Table 2 show a cold core.

The simulation domain is another factor affecting the reproduction of observed medicanes. The set of AWI/ GERICS simulations stands out from the rest, as very few of the observed medicanes are detected in them. This is likely related to the domain used in those runs, which is much bigger than in other simulations and covers the whole Atlantic tropical area. The differences with the other

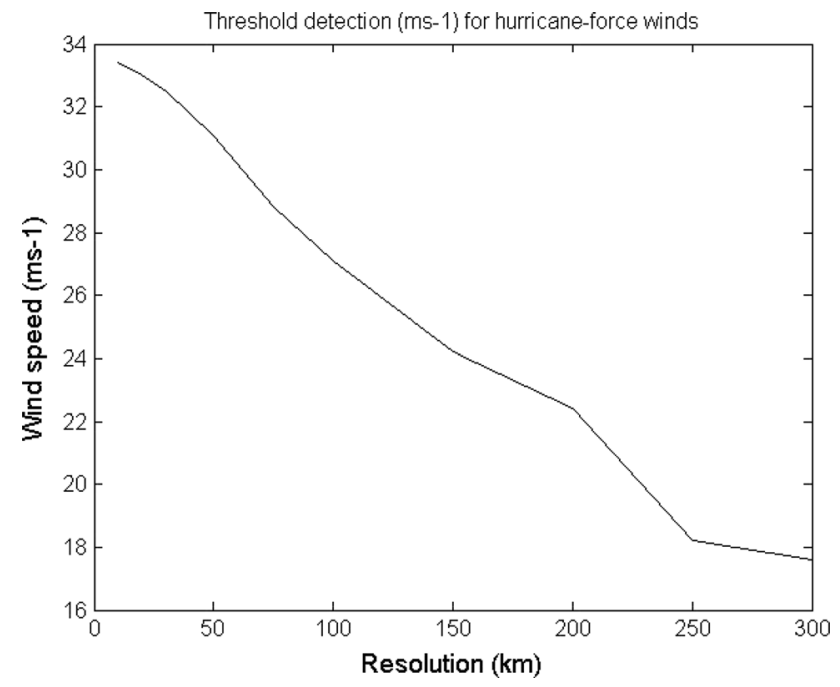

Fig. 3 Windspeed threshold (m/s) for hurricane-force wind detection as a function of model resolution $(\mathrm{km})$

REMO simulations are also likely due to differences in the domain extension, as GERICS-REMO uses the (much smaller) EURO-CORDEX domain. An additional reason for the deviating results of AWI/GERICS runs could be that it is nested in ERA40 instead of in ERA-Interim reanalysis.

On the other hand, the models simulate medicanes that do not coincide in date with the observed ones, but occur in favorable environments for their development. A visual examination of the synoptic setting for several simulated intense medicanes indicates that they typically appear under observed cut-off lows. The different models also simulate different cases. These facts indicate that medicanes have a clear stochastic component, and the evaluation of their simulation in climate models should be made statistically. Hereafter we analyze several statistical measures for them.

\subsection{Impact of increased resolution}

In order to adequately consider the effect of horizontal resolution on the simulation of medicanes, first we should take into account how the resolution affects the cyclone intensity. As we are dealing with tropical-like cyclones, we will use the criteria presented by Walsh et al. (2007) for obtaining a resolution-dependent threshold for tropical storms, which have maximum surface winds above $17.5 \mathrm{~m} / \mathrm{s}$. Winds in tropical cyclones reach a maximum at a relatively small distance from the cyclone center, decreasing rapidly with increasing distance. Therefore, if we sample the winds using a larger grid spacing (coarser resolution), a smaller wind maximum will be simulated. Following Walsh et al. (2007), for the resolutions used in the present study, the threshold values for tropical storm intensity are $16.5 \mathrm{~m} / \mathrm{s}$ 


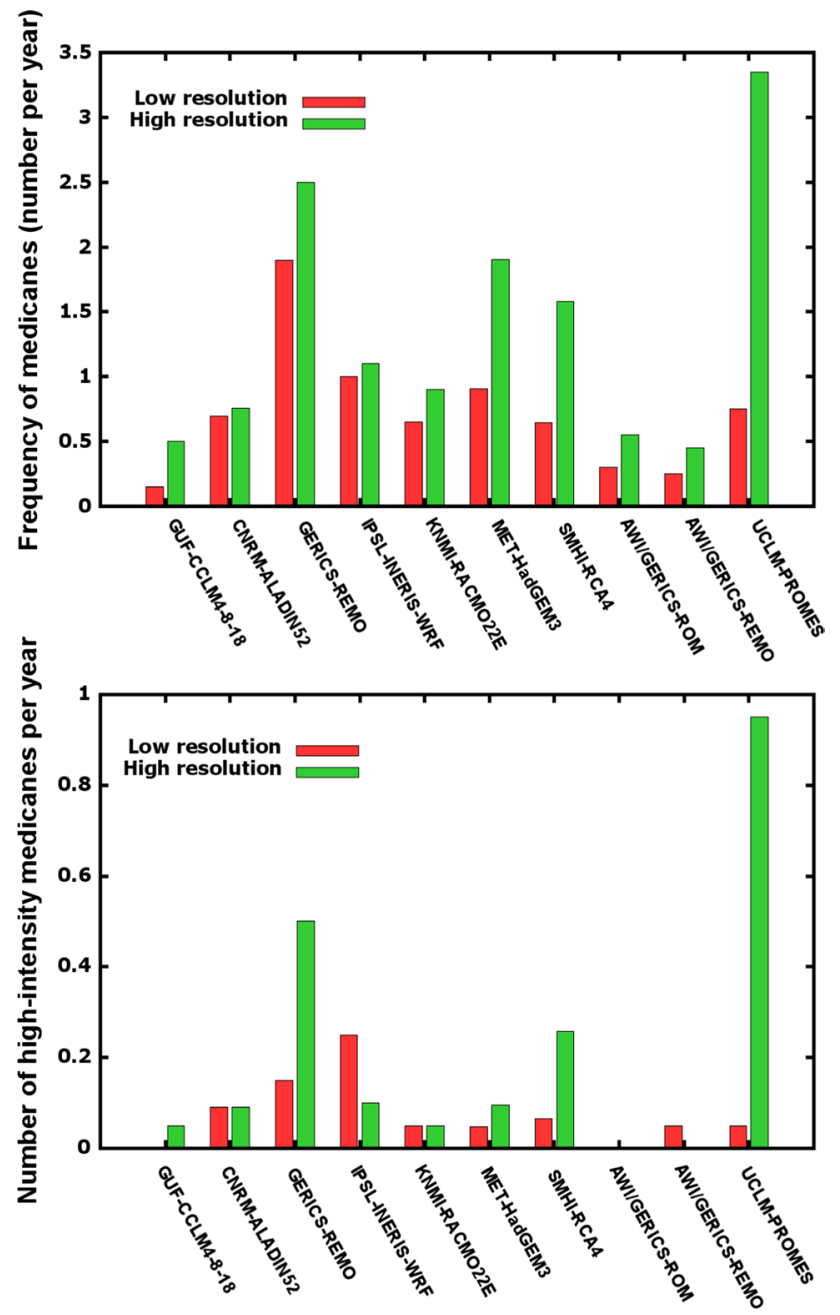

Fig. 4 Frequency of medicanes (cyclones per year) (upper panel) and frequency of high-intensity medicanes (above $25.5 \mathrm{~m} / \mathrm{s}$ ) (lower panel) for pairs of lower resolution (red bars) and higher resolution simulations (green bars)

(for a $50 \mathrm{~km}$ grid spacing) and $17.5 \mathrm{~m} / \mathrm{s}$ (for a $12.5 \mathrm{~km}$ grid spacing). The application of the same method for hurricane intensity $(33.5 \mathrm{~m} / \mathrm{s}$, corresponding to 65 knots) yields the curve of Fig. 3. The threshold values for this intensity are $31 \mathrm{~m} / \mathrm{s}$ (for $50 \mathrm{~km}$ ) and $33.5 \mathrm{~m} / \mathrm{s}$ (for $12.5 \mathrm{~km}$ ). Therefore, intensities of $16.5 \mathrm{~m} / \mathrm{s}$ and $31 \mathrm{~m} / \mathrm{s}$ in the low resolution simulations are respectively equivalent to intensities of $17.5 \mathrm{~m} / \mathrm{s}$ and $33.5 \mathrm{~m} / \mathrm{s}$ in high-resolution runs. Equivalent values for other intensities are obtained through a linear interpolation between those values.

Figure 4 (upper panel) shows the yearly frequency of medicanes for the different low/high resolution pairs of simulations using the same model (most of them have $50 / 12.5 \mathrm{~km}$ grid spacings). There is a clear frequency increase with resolution, which is systematic (all models show it) and generally strong (in six out of ten models, the frequency increases nearly two times or more). Whereas most of the low resolution simulations underestimate the observed frequency of about 1 medicane/year found in our reference database [and even more the value of 1.5 medicanes/year in Cavicchia et al. (2013)], the high resolution simulations show an improvement, with values generally nearer to the observed value. There is a large spread among models, with appreciable overestimations and underestimations of the observed frequencies.

Regarding the effect of resolution on cyclone intensity, we have clustered the distribution in two groups (moderate intensity: $17.5-25.5 \mathrm{~m} / \mathrm{s}$, and high intensity: above 25.5 $\mathrm{m} / \mathrm{s}$ ). The small number of medicanes in many simulations hinders the use of percentiles, obtained directly from the simulated values, for analysing intensity changes. Figure 4 (lower panel) shows the number of high-intensity medicanes per year for each pair of low/high resolution runs. The reference database gives a value of about 0.5 highintensity medicanes per year. The strong underestimation of high intensity medicanes in the $50 \mathrm{~km}$ simulation (with values between 0 and 0.2 medicanes per year) is not corrected by many of the high-resolution simulations. Only three high-resolution simulations show a strong increase of high-intensity medicanes. The average simulated intensity (not shown) confirms the difficulties of most models in reproducing high intensity: the negative bias found in low resolution simulations (the observed value is of about $27 \mathrm{~m} / \mathrm{s}$, while the simulated values lie between 19 and $22 \mathrm{~m} / \mathrm{s}$ ) is not appreciably improved by the increase in resolution in most of the models. Intensity changes seem to be strongly model-dependent, and increased resolution alone does not improve the intensity of the simulated medicanes.

The spatial distribution of medicanes is shown in Table 3. In the reference database, the highest number of medicanes is found in the central area (around Italy and to the south of it), followed by the western area. The lowest number of medicanes is detected over the eastern Mediterranean. Other observed databases like that of Tous and Romero (2013) show similar spatial locations. The RCMs reproduce well the eastern minimum, and on average the high resolution runs improve the distribution between the western and central Mediterranean areas. The north-south distribution is well captured by both low and high resolution simulations. An important aspect of observed medicanes is that their distribution is clearly displaced to the south when compared to the spatial distribution of all Mediterranean cyclones, which has a strong maximum around the Gulf of Genoa. The distribution of simulated medicanes also reproduces well this displacement to the south with respect to the typical baroclinic cyclones.

Table 3 also shows the monthly distribution of medicanes. The reference database shows a clear autumn maximum (September and October), while the percentage of winter medicanes is smaller than in the simulations. However, 
Table 3 Spatial and temporal distribution of medicanes

\begin{tabular}{|c|c|c|c|c|c|c|c|c|c|c|c|}
\hline & \multicolumn{5}{|c|}{ Spatial distribution (\%) } & \multicolumn{6}{|c|}{ Monthly distribution (\%) } \\
\hline & West & Center & East & North & South & Aug. & Sep. & Oct. & Nov. & Dec. & Jan. \\
\hline Reference database & 33 & 50 & 17 & 67 & 33 & 0 & 33 & 33 & 17 & 17 & 0 \\
\hline Low-resolution ensemble mean & 52 & 33 & 15 & 67 & 33 & 1 & 4 & 25 & 33 & 19 & 18 \\
\hline High-resolution ensemble mean & 42 & 45 & 13 & 64 & 36 & 1 & 5 & 17 & 34 & 22 & 21 \\
\hline Uncoupled ensemble mean & 39 & 47 & 14 & 59 & 41 & 1 & 1 & 17 & 34 & 23 & 24 \\
\hline Coupled ensemble mean & 47 & 41 & 12 & 65 & 35 & 1 & 2 & 10 & 26 & 28 & 33 \\
\hline
\end{tabular}

Left part of the table: relative spatial distribution of medicanes (percentage of total medicanes) from August to January

Zonal division in three areas: Western Mediterranean (lon $<10 \mathrm{E})$, Central Mediterranean $(10 \mathrm{E}<$ lon $<24 \mathrm{E})$ and Eastern Mediterranean (lon > 24E). Meridional division in two zones: North (lat $>38 \mathrm{~N}$ ) and South (lat $<38 \mathrm{~N}$ ). Right part of the table: monthly distribution of medicanes (percentage of total medicanes) from August to January. The results are shown for the ensemble means of low/high resolution runs and uncoupled/coupled runs

the appearance of January medicanes in the simulations is similar to that observed in other climatologies like Tous and Romero (2013) or Cavicchia et al. (2013). Differently from the reference database, the latter climatologies include also the 1990s and the 1980s and thus cover all the years analyzed in the simulations. An increase in the relative percentage of winter medicanes is found with higher resolution.

It can also be seen in Table 3 that the observed high percentage of September medicanes is not well captured by the models. No improvement is found in that respect in the high resolution runs. Model formulation seems to be more important than resolution for the representation of these medicanes, as only a few models are able to simulate them better. The difficulties of models in the representation of September medicanes probably depend on their intensity, as they are generally among the least intense medicanes (as can be seen from their division in Tables 1,2). The intensity of the baroclinic disturbance originating them is also frequently weaker than in other autumn or winter months, which could complicate their successful simulation.

\subsection{Impact of ocean-atmosphere coupling}

The frequency of medicanes for the pairs of coupled/ uncoupled runs is presented in Fig. 5 (upper panel). No clear frequency change is found between them: the changes are generally small and of differing signs. The effect of coupling on the number of high-intensity medicanes can be seen in the lower panel of Fig. 5. Some tendency towards a lower number of intense medicanes is found in coupled simulations, but changes are rather small. Thus the hypothesis that air-sea interaction in the coupled runs can produce a negative feedback is not clearly confirmed. The low resolution of several models could be a reason for the lack of clear changes. Akhtar et al. (2014) found that coupled runs improved the simulation of medicanes in the case of high resolution (about $10 \mathrm{~km}$ ), but not for lower resolutions.
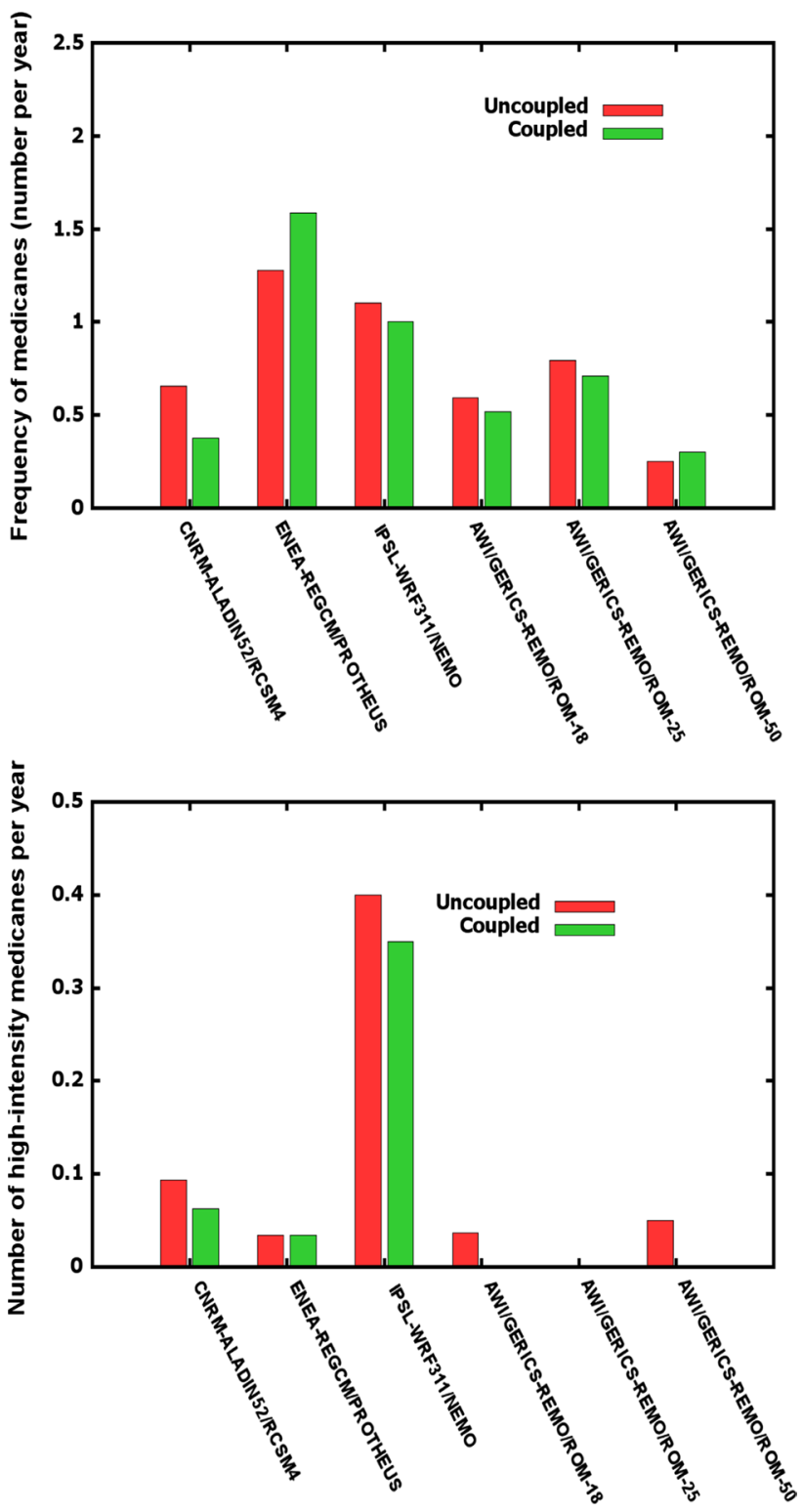

Fig. 5 As in Fig. 4, but for pairs of uncoupled (red bars) and coupled (green bars) simulations 

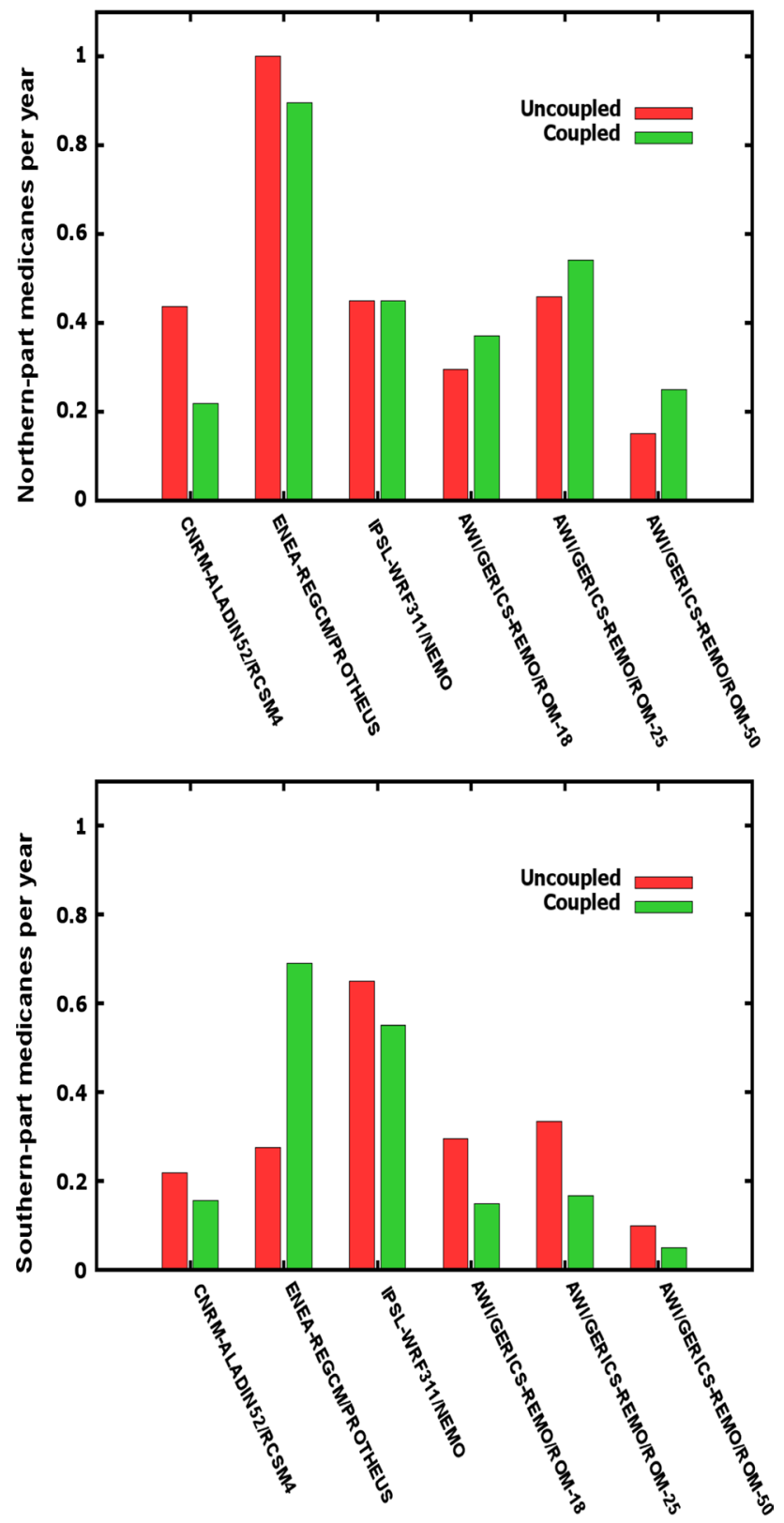

Fig. 6 Number of medicanes per year, north of $38 \mathrm{~N}$ (upper panel) and south of $38 \mathrm{~N}$ (lower panel), for pairs of uncoupled and coupled simulations

The general underestimation of intensity in simulated medicanes can also limit the effect of coupling, as its effect should be stronger for higher intensities of cyclones (and more intense air-sea exchanges).

Aggregate values presented before, like the frequency and intensity statistics, might be hiding information about the underlying mechanisms of development. Interesting results are found if we separate the medicanes spatially and temporally. Figure 6 shows the number of medicanes per year north and south of $38 \mathrm{~N}$. The changes in the northern part of the Mediterranean Sea depend on the model. But the variations in the southern part of the Mediterranean Sea are more systematic: five of the six simulations simulate less medicanes in this area in the case of coupled runs. The only exception is the ENEA coupled simulation, in which a strong increase of medicanes is simulated in the southern part. Relative values shown for the ensemble mean in Table 3 indicate also an overall reduction of medicanes in the southern part in the coupled simulations.

Table 3 shows another remarkable result: the relative monthly distribution of medicanes shows a distinct reduction of autumn medicanes and a corresponding increase of winter medicanes in the coupled runs. The strongest change occurs for January medicanes, with an increase from $24 \%$ in the uncoupled runs to $33 \%$ in the coupled runs. There is even a rise in the absolute number of January medicanes for ENEA-PROTHEUS and AWI-ROM coupled models. On the other hand, the absence of September medicanes is not corrected by the use of coupling.

The opposite changes in autumn and winter medicanes in the coupled runs might be related to the oceanic mixed layer depth. As shown by D'Ortenzio (2005), the Mediterranean mixed layer is very shallow in summer, and reaches the maximum depth in winter. Mixed layer depth can control the magnitude of the negative intensity feedback due to air-sea coupling. If the oceanic mixed layer is shallow, cold waters from below the mixed layer will be lifted to the surface due to air-sea interaction, reducing the SST. But if the mixed layer is deep, the emerging deeper water will maintain basically the same SST, limiting or canceling the negative feedback. There are even cases where the air-sea feedback can be positive (Shay et al. 2000). Significantly, medicanes are not observed in summer, despite the higher SST values. They appear in autumn, when SSTs decrease but the mixed layer depth increases, or in winter, when SSTs are low but the mixed layer depth is at its maximum.

In order to clarify the impact of coupling and the possible influence of the oceanic mixed layer depth, we have looked in more detail at two individual simulated cyclones that show opposite behaviour with respect to the effect of coupling on simulated intensity. The simulated cyclones are taken from the CNRM-ALADIN52/RCSM4 pair of simulations. The first case is a cyclone simulated in December 1996: the uncoupled run generates a rather intense cyclone ( $23 \mathrm{~m} / \mathrm{s}$ of maximum surface wind) with a full-tropospheric warm core, while the coupled run strongly reduces strongly the intensity of the cyclone. This can be well observed in the mean sea level pressure maps for 9 December 1996 of Fig. 7 (uncoupled run in the upper panel, coupled run in the lower panel). The SSTs under the cyclone centers (represented through shaded circles) show noticeable differences in both runs. At the beginning of the track, the SST is slightly higher $\left(0.3{ }^{\circ} \mathrm{C}\right)$ in the coupled run than in 
Fig. 7 Simulated cyclone of 9 December 1996 in the uncoupled run (CNRM-ALADIN52-50; upper panel) and in the coupled run (CNRMRCSM4; lower panel). The contours show mean sea level pressure $(\mathrm{hPa})$ when the simulated cyclone reaches its maximum intensity. The shaded circles show sea surface temperature $\left({ }^{\circ} \mathrm{C}\right)$ for consecutive 6-hourly cyclone center locations from the first location over sea (labeled with an "A") to the location of the maximum intensity (labeled with a "Z”)
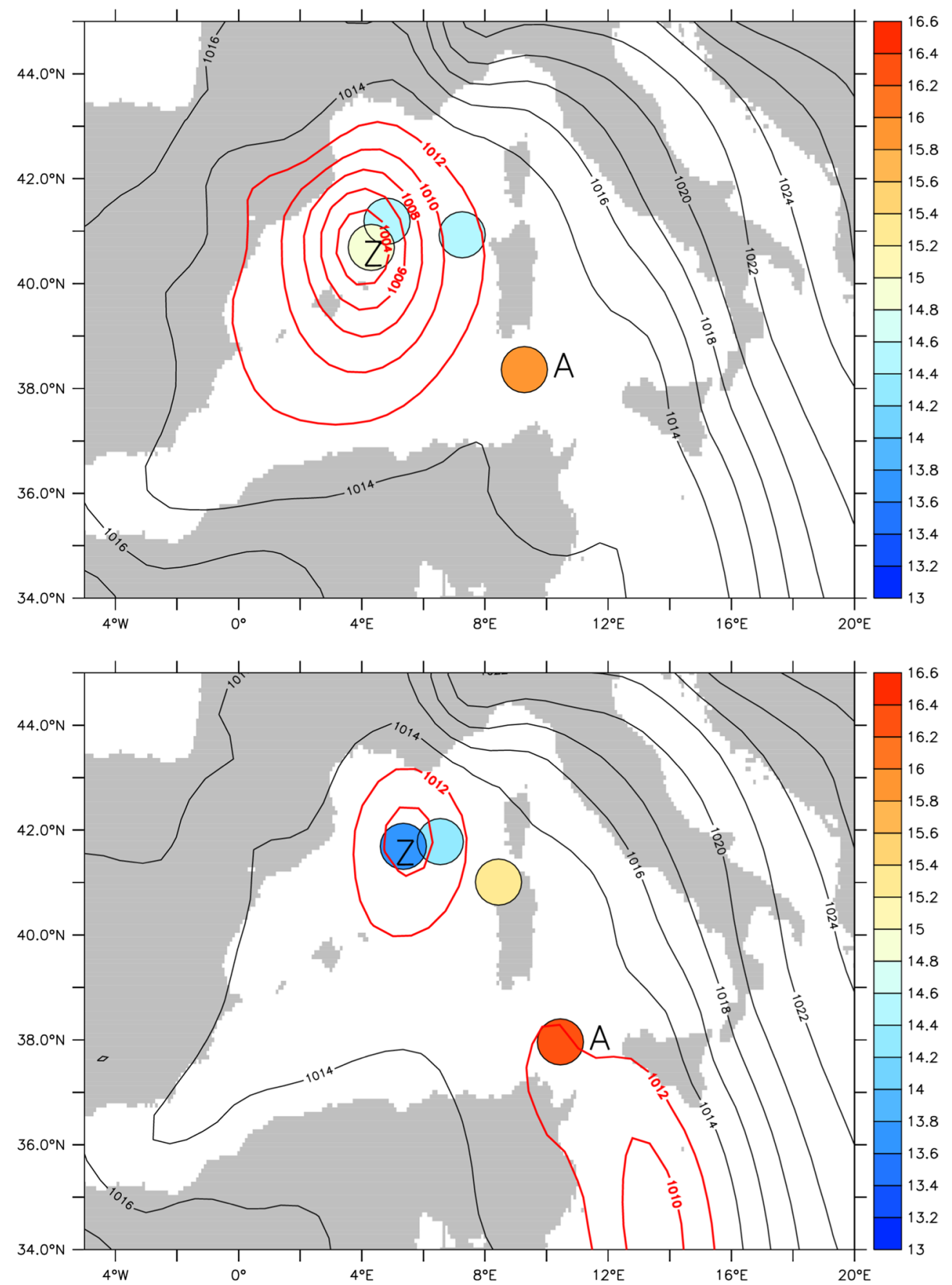

the uncoupled run, but for the last represented track point (when the cyclone reaches its maximum intensity) the SST is clearly lower $\left(1.2^{\circ} \mathrm{C}\right)$ in the coupled run. The simulated SSTs in the coupled run (Fig. 8, upper panel) show a complex mesoscale structure. Particularly, the lowest SSTs are not found right at the northern coast (as in the uncoupled run), but further south, precisely under the track of the simulated cyclone in the coupled run. The intensity differences due to the coupling can be well explained by the SST differences, as the cyclone in the uncoupled run moves over warmer waters. The mixed layer depth for the coupled run is shown in the lower panel of Fig. 8. The low SST values at the end of the track coincide with an area of low values of the mixed layer depth. The mixed layer depth shows also a high spatial variability. A rather good overlap can be seen between the spatial distribution of SST and mixed layer depth in the coupled run, as relatively low values of SST correspond to low values of the mixed layer depth.

The second case corresponds to January 1980. A medicane appears in the coupled simulation, but not in the uncoupled run as the warm core criteria are not met there. The intensity is higher in the coupled run $(25.4 \mathrm{~m} / \mathrm{s}$ 
Fig. 8 Simulated cyclone of 9 December 1996 in the coupled run (CNRM-RCSM4). Sea surface temperature $\left({ }^{\circ} \mathrm{C}\right)$ and oceanic mixed layer depth $(\mathrm{m})$ The cyclone track is superimposed, using the same labeling as in Fig. 5

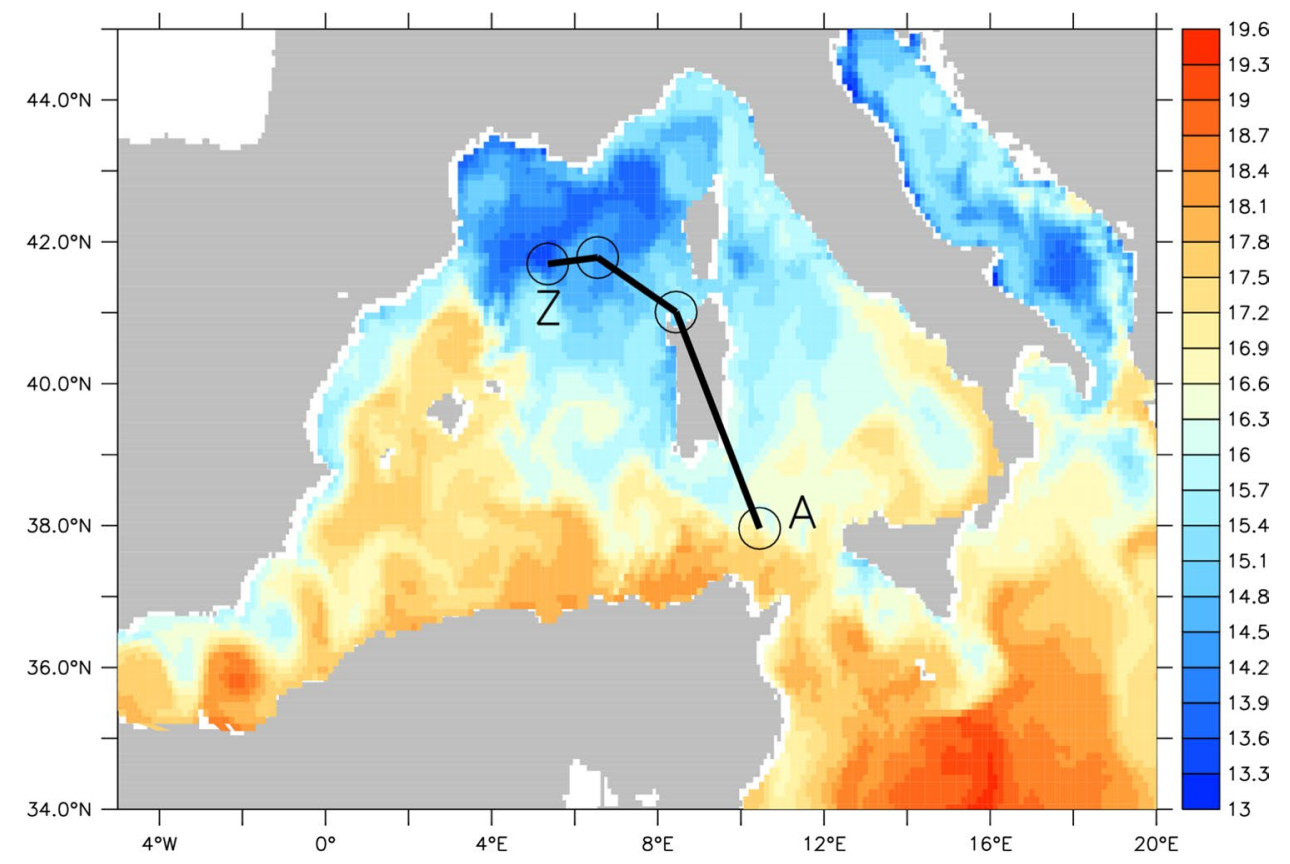

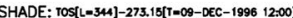

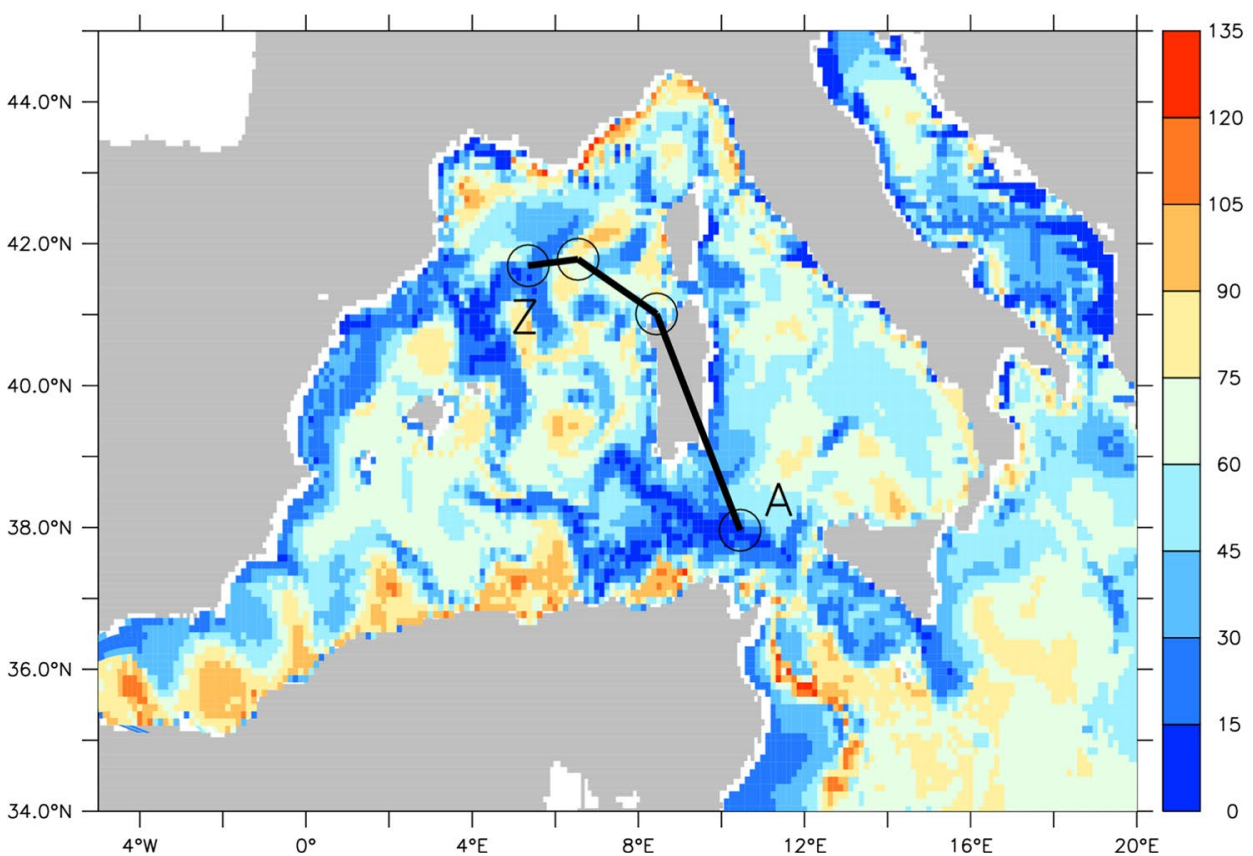

of maximum surface wind) than in the uncoupled run $(21.8 \mathrm{~m} / \mathrm{s})$. The location of the cyclone is similar in both runs, as shown in Fig. 9, but there are important differences in the SSTs, with clearly higher values $\left(1{ }^{\circ} \mathrm{C}\right)$ in the coupled run at the beginning of the track. The comparatively warm water north of Algeria in the coupled run extends under a significant part of the track of the cyclone (see Fig. 10). Mixed layer depth values are generally higher than for the first case, and they show again an interesting overlap with SST features: the relatively high SST tongue north of Algeria coincides with an area of deep mixed layer.
The two opposite cases indicate that the coupling can act differently depending on the distribution of SST, and that the mixed layer depth might have some effect on mesoscale SST features.

\section{Concluding remarks}

In the context of the impacts of climate change on tropical cyclones, an important issue is whether areas that now support only marginally the development of tropical cyclones, 
Fig. 9 As in Fig. 7, but for the simulated cyclone of 15 January 1980
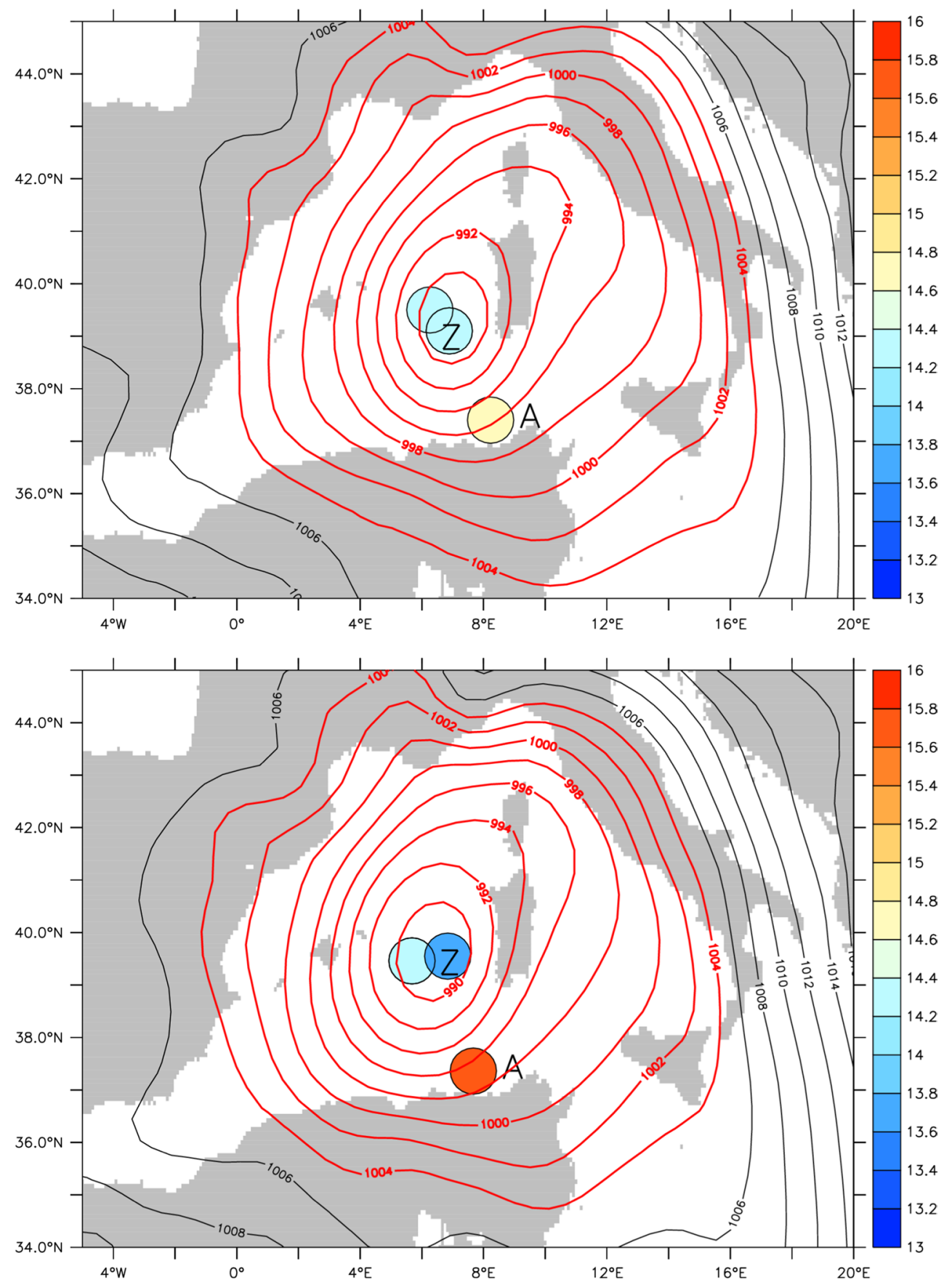

like the Mediterranean Sea, will experience an increase of tropical cyclone activity in the future. A poleward extension of the effects of tropical cyclones is a potential result of global warming. Previous studies of climate change projections, based generally on individual atmospheric models, have indicated that medicanes (Mediterranean tropical-like cyclones) could increase in intensity in the future. Large ensembles of high resolution and ocean-atmosphere coupled regional climate model (RCM) simulations are now available from MedCORDEX and EURO-CORDEX projects, representing an opportunity to update and improve the assessment of the impact of climate change on medicanes. As a first step towards such an improved assessment, we analyze the ability of the RCMs used in these projects to reproduce the observed characteristics of medicanes, and the impact of increased resolution and air-sea coupling on their simulation.

Medicanes are generated through tropical transition, which is a complex process including factors over a wide range of scales, from synoptic-scale upper level cut-off lows to small-scale convection. This complexity raises the following issue: can observed medicanes be reproduced 
Fig. 10 As in Fig. 8, but for the simulated cyclone of 15 January 1980
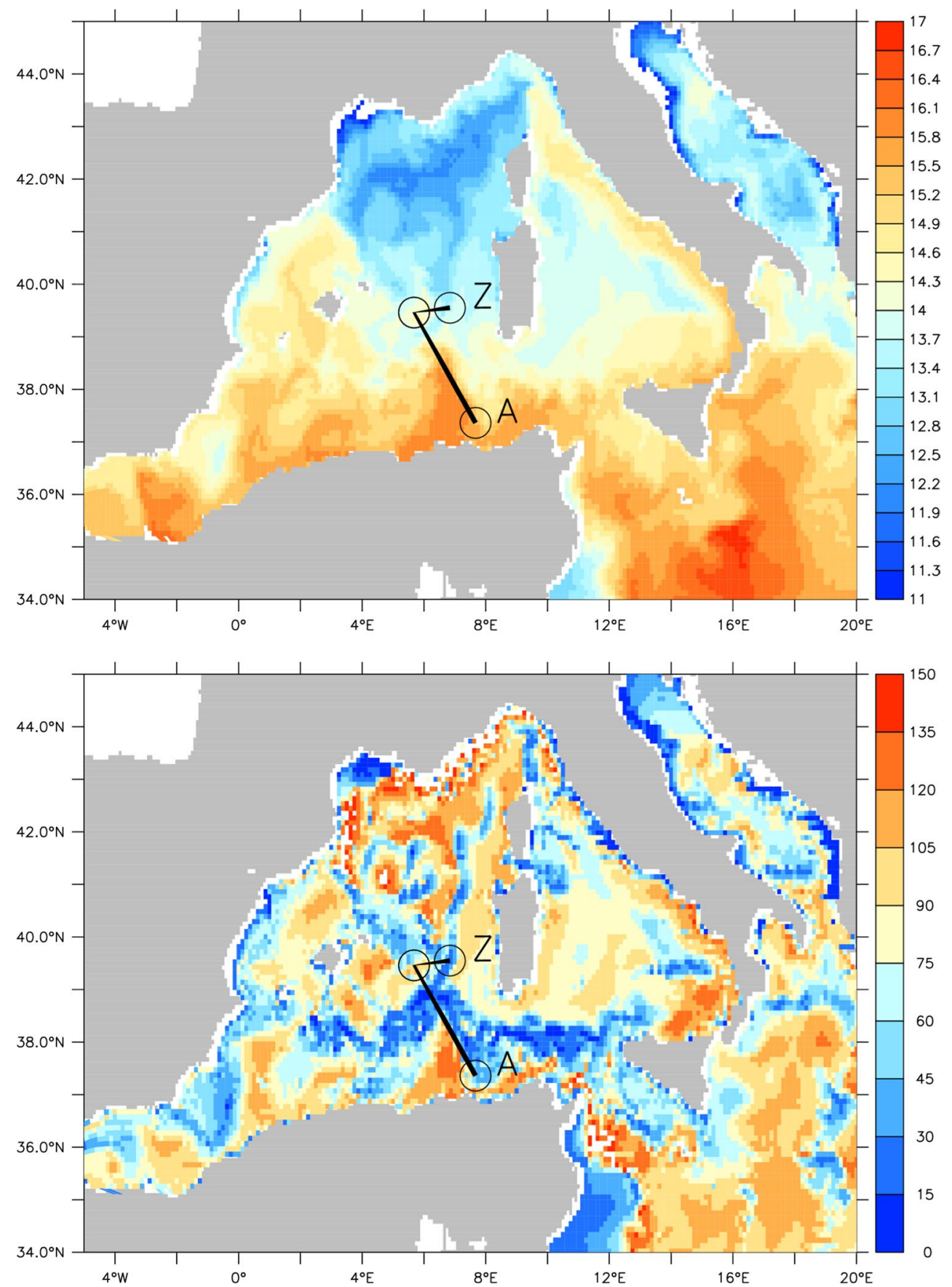

in climate-mode simulations on a case-by-case basis? We have examined if the RCMs replicate the observed medicane cases through comparison with an observationalnumerical database. Results indicate that in most cases, models generate medicanes at dates that are not coincident with actual medicanes. There are some exceptions to this, suggesting that the likelihood that an RCM replicates an actual medicane is higher when the observed medicane has a long tropical phase and is intense. In agreement with the existence of two different types of tropical transition, suggested by Davis and Bosart (2004), the intensity of the precursor baroclinic disturbance also seems to be important for the reproduction of observed medicanes. This may explain in part the difficulties of RCMs for simulating September medicanes, as these medicanes originate typically from relatively weak cut-off lows.

There are several reasons why an actual medicane is not replicated by RCMs: a hybrid cyclone with a partially tropical structure is sometimes simulated, or the simulation maintains the cold core structure of the initial cyclone. In some cases, the simulated cyclones do not reach the minimum intensity $(17.5 \mathrm{~m} / \mathrm{s})$ required for their detection. 
There is a general underestimation of medicane intensity, which is well illustrated by the case of a model applying spectral nudging: all high-intensity observed medicanes (with a maximum surface wind above $25 \mathrm{~m} / \mathrm{s}$ ) are reproduced by it as cyclones with wind speed above $17.5 \mathrm{~m} / \mathrm{s}$, but most lower-intensity cases are not detected in these simulations. The absence of coincidence (on a case-by-case basis) between climate simulations and observations can be expected due to the complicated genesis and structure of medicanes and their small size, and has been observed in previous studies (Walsh et al. 2014). As a consequence, the evaluation of medicanes in long regional climate model simulations (without reinitialisation of the atmospheric fields) should be done statistically.

Pairs of low and high resolution runs and pairs of uncoupled and coupled runs have been compared to analyze the impact of resolution and coupling on the simulation of medicanes. The use of increased resolution shows a systematic and generally strong impact on the frequency of medicanes. Higher frequency is simulated when the grid spacing is reduced, representing an improvement in most cases. But unexpectedly, the negative bias in the intensity of medicanes is not corrected by most higher-resolution runs. The intensity seems to depend more on the model formulation than on resolution alone.

For tropical cyclones in other basins, air-sea interaction frequently produces a negative feedback on the intensity of cyclones, as the enhanced vertical mixing in the ocean under strong winds transports colder deep water to the surface. But if the oceanic mixed layer below the cyclone is deep, the negative feedback is inhibited. The lack of a clear overall effect of coupling on the frequency or intensity of the simulated medicanes might be due to the influence of such contradicting factors. A hint in this direction is provided by the detailed analysis of two specific cyclones, and the distinct seasonal shift of medicanes in the coupled simulations from autumn to winter supports this explanation. The negative feedback should be clearer for medicanes in September, when the mixed layer is very shallow, but only a small number of September medicanes have been simulated by the models. This could be a further reason for the limited effect of coupling.

The possible influence of the oceanic mixed layer depth on the interaction between medicanes and the sea should be analysed in a detailed way in future studies. But in case it is confirmed, it could have important consequences for the future evolution of medicanes, as projections of the Mediterranean mixed layer depth show important future changes, which depend on the emissions scenario (Adloff et al. 2015). This would increase the utility of applying ocean-atmosphere coupled RCMs for climate change studies.
Acknowledgements This work is part of the Med-CORDEX initiative (www.medcordex.eu) supported by the HyMeX programme (www.hymex.org). Part of the data used in this work have been downloaded from the Med-CORDEX database (www.medcordex.eu). The authors like to thank the coordination and participating institutes of the EURO-CORDEX initiative (www.euro-cordex.net). The work of UCLM group has been funded by the grant CGL2010-18013 (Spanish Ministry of Science and Innovation) and grant CGL2013-47261-R (Spanish Ministry of Economy and Competitivity). These grants have been co-funded by the European Regional Development Fund. AWI simulations were performed at the German Climate Computing Center (DKRZ). The work of Dmitry Sein was supported by the German Federal Ministry of Education and Research (BMBF) under the project SPACES-AGULHAS (research Grant 03G0835B). The REMO (GERICS) simulations were supported by BMBF and performed under the "Konsortial" share at the German Climate Computing Centre (DKRZ). Bodo Ahrens acknowledges support from Senckenberg BiK-F. The calculations for WRF IPSL-INERIS were made in collaboration with R. Vautard (IPSL/CNRS) using the TGCC super computers under the GENCI time allocation GEN6877. The work of Sophie Bastin has received funding from the French National Research Agency (ANR) projects REMEMBER (Contract ANR12-SENV-001) and granted access to the HPC resources of IDRIS (under allocation i2011010227). The KNMI-RACMO2 simulations were supported by the Dutch Ministry of Infrastructure and the Environment. Part of the SMHI contribution was carried out in the Swedish Mistra-SWECIA programme founded by Mistra (the Foundation for Strategic Environmental Research).

\section{References}

Adloff F, Somot S, Sevault F et al (2015) Mediterranean sea response to climate change in an ensemble of twenty first century scenarios. Clim Dyn 45:2775-2802

Akhtar N, Brauch J, Dobler A et al (2014) Medicanes in an oceanatmosphere coupled regional climate model. Nat Hazards Earth Syst Sci 14:2189-2201

Artale V, Calmanti S, Carillo A et al (2010) An atmosphere-ocean regional climate model for the Mediterranean area: assessment of a present climate simulation. Clim Dyn 35:721-740

Brossier CL, Bastin S, Béranger K, Drobinski P (2015) Regional mesoscale air-sea coupling impacts and extreme meteorological events role on the Mediterranean Sea water budget. Clim Dyn 44:1029-1051

Cavicchia L, von Storch H, Gualdi S (2013) A long-term climatology of medicanes. Clim Dyn 43:1183-1195

Cavicchia L, von Storch H, Gualdi S (2014) Mediterranean tropicallike cyclones in present and future climate. J Clim 27:7493-7501

Chaboureau JP, Pantillon F, Lambert D et al (2012) Tropical transition of a Mediterranean storm by jet crossing. Q J R Meteorol Soc 138:596-611

Colin J, Déqué M, Radu R, Somot S (2010) Sensitivity study of heavy precipitation in limited area model climate simulations: influence of the size of the domain and the use of the spectral nudging technique. Tellus A 62:591-604

D’Ortenzio F (2005) Seasonal variability of the mixed layer depth in the Mediterranean Sea as derived from in situ profiles. Geophys Res Lett 32:L12605

Davis CA, Bosart LF (2004) The TT problem: forecasting the tropical transition of cyclones. Bull Am Meteorol Soc 85:1657-1662

Domínguez M, Gaertner MA, De Rosnay P, Losada T (2010) A regional climate model simulation over West Africa: parameterization tests and analysis of land-surface fields. Clim Dyn 35:249-265 
Domínguez M, Romera R, Sánchez E et al (2013) Present-climate precipitation and temperature extremes over Spain from a set of high resolution RCMs. Clim Res 58:149-164

Emanuel KA (1987) An air-sea interaction model of intraseasonal oscillations in the tropics. J Atmos Sci 44:2324-2340

Emanuel KA (1999) Thermodynamic control of hurricane intensity. Nature 401:665-669

Emanuel K (2005) Genesis and maintenance of "Mediterranean hurricanes". Adv Geosci 2:217-220

Evans JL, Braun A (2012) A climatology of subtropical cyclones in the South Atlantic. J Clim 25:7328-7340

Fita L, Romero R, Luque A et al (2007) Analysis of the environments of seven Mediterranean tropical-like storms using an axisymmetric, nonhydrostatic, cloud resolving model. Nat Hazard Earth Sys 7:41-56

Flaounas E, Drobinski P, Vrac M et al (2013) Precipitation and temperature space-time variability and extremes in the Mediterranean region: evaluation of dynamical and statistical downscaling methods. Clim Dyn 40:2687-2705

Gaertner MA, Jacob D, Gil V et al (2007) Tropical cyclones over the Mediterranean Sea in climate change simulations. Geophys Res Lett 34:L14711

Garde LA, Pezza AB, Tristram Bye JA (2010) Tropical transition of the 2001 Australian duck. Mon Weather Rev 138:2038-2057

González-Alemán JJ, Valero F, Martín-León F, Evans JL (2015) Classification and synoptic analysis of subtropical cyclones within the northeastern Atlantic Ocean. J Clim 28:3331-3352

Guishard MP, Evans JL, Hart RE (2009) Atlantic subtropical storms Part II: climatology. J Clim 22:3574-3594

Hart RE (2003) A cyclone phase space derived from thermal wind and thermal asymmetry. Mon Weather Rev 131:585-616

Herrmann M, Somot S, Calmanti S et al (2011) Representation of spatial and temporal variability of daily wind speed and of intense wind events over the Mediterranean Sea using dynamical downscaling: impact of the regional climate model configuration. Nat Hazard Earth Syst 11:1983-2001

Homar V, Romero R, Stensrud DJ et al (2003) Numerical diagnosis of a small, quasi-tropical cyclone over the western Mediterranean: dynamical vs. boundary factors. Q J R Meteorol Soc 129:1469-1490

Jacob D, Elizalde A, Haensler A et al (2012) Assessing the transferability of the regional climate model REMO to different coordinated regional climate downscaling experiment (CORDEX) regions. Atmosphere 3:181-199

Jacob D, Petersen J, Eggert B et al (2014) EURO-CORDEX: new high-resolution climate change projections for European impact research. Reg Environ Chang 14:563-578

Kossin JP, Emanuel KA, Vecchi GA (2014) The poleward migration of the location of tropical cyclone maximum intensity. Nature 509:349-352

Kothe S, Panitz H-J, Ahrens B (2014) Analysis of the radiation budget in regional climate simulations with COSMO-CLM for Africa. Meteorol Z : 123-141

Kupiainen M, Samuelsson P, Jones C, et al (2011) Rossby centre regional atmospheric model, RCA4. Rossby Center News Letter

Miglietta MM, Laviola S, Malvaldi A et al (2013) Analysis of tropical-like cyclones over the Mediterranean Sea through a combined modeling and satellite approach. Geophys Res Lett 40:2400-2405
Moscatello A, Miglietta MM, Rotunno R (2008) Observational analysis of a Mediterranean "hurricane" over south-eastern Italy. Weather 63:306-311

Moufouma-Okia W, Jones R (2014) Resolution dependence in simulating the African hydroclimate with the HadGEM3-RA regional climate model. Clim Dyn 44:609-632

Picornell MA, Jansa A, Genovés A, Campins J (2001) Automated database of mesocyclones from the HIRLAM (INM) $-0.5^{\circ}$ analyses in the western Mediterranean. Int J Climatol 21:335-354

Pytharoulis I, Craig G, Ballard S (2000) The hurricane-like Mediterranean cyclone of January 1995. Meteorol Appl 7:261-279

Reale O, Atlas R (2001) Tropical cyclone-like vortices in the extratropics: observational evidence and synoptic analysis. Weather Forecast 16:7-34

Rockel B, Will A, Hense A (2008) The regional climate model COSMO-CLM (CCLM). Meteorol Z 17:347-348

Romero R, Emanuel K (2013) Medicane risk in a changing climate. J Geophys Res Atmos 118:5992-6001

Ruti PM, Somot S, Giorgi F et al (2015) MED-CORDEX initiative for Mediterranean climate studies. Bull Am Meteorol Soc 97:1187-1208

Samuelsson P, Jones CG, Willén U et al (2011) The Rossby centre regional climate model RCA3: model description and performance. Tellus A 63:4-23

Sein DV, Mikolajewicz U, Gröger M et al (2015) Regionally coupled atmosphere-ocean-sea ice-marine biogeochemistry model ROM: 1. description and validation. J Adv Model Earth Syst 7:268-304

Sevault F, Somot S, Alias A et al (2014) A fully coupled Mediterranean regional climate system model: design and evaluation of the ocean component for the 1980-2012 period. Tellus A 66:23967

Shay LK, Goni GJ, Black PG (2000) Effects of a warm oceanic feature on hurricane opal. Mon Weather Rev 128:1366-1383

Skamarock WC, Klemp JB, Dudhia J et al (2008) A description of the advanced research WRF version 3, NCAR, Tech. Note, Mesoscale and Microscale Meteorology Division

Stéfanon M, Drobinski P, D'Andrea F et al (2014) Soil moisturetemperature feedbacks at meso-scale during summer heat waves over Western Europe. Clim Dyn 42:1309-1324

Tous M, Romero R (2013) Meteorological environments associated with medicane development. Int J Climatol 33:1-14

Tous M, Zappa G, Romero R et al (2016) Projected changes in medicanes in the HadGEM3 N512 high-resolution global climate model. Clim Dyn 47:1913-1924

van Meijgaard E, van Ulft L, Lenderink G et al (2012) Refinement and application of a regional atmospheric model for climate scenario calculations of Western Europe. Climate changes spatial planning publication: KvR 054/12. ISBN: 978-90-8815-046-3, p 44. http:// climexp.knmi.nl/publications/FinalReport_KvR-CS06.pdf

Vautard R, Gobiet A, Jacob D et al (2013) The simulation of European heat waves from an ensemble of regional climate models within the EURO-CORDEX project. Clim Dyn 41:2555-2575

Walsh KJE, Fiorino M, Landsea CW, McInnes KL (2007) Objectively determined resolution-dependent threshold criteria for the detection of tropical cyclones in climate models and reanalyses. J Clim 20:2307-2314

Walsh KJE, Giorgi F, Coppola E (2014) Mediterranean warm-core cyclones in a warmer world. Clim Dyn 42:1053-1066

Walsh KJE, Mcbride JL, Klotzbach PJ et al (2016) Tropical cyclones and climate change. WIREs Clim Change 7:65-89 